\title{
Monitoring Bioadhesion and Biofim Formation Within Biopits in Archaeological Potsherds by Microscopic Techniques
}

Daiana Soto $^{1^{*}}$, Anna Otlewska ${ }^{2}$, Katarzyna Rajkowska $^{2}$, Beata Gutarowska ${ }^{2}$, Patricia Guiamet ${ }^{3,4}$

1. Laboratorio de Arqueometría, Instituto de Arqueología (ArqueoLab-IA), Universidad de Buenos Aires, CABA, Argentina.

2. Institute of Fermentation Technology and Microbiology, Lodz University of Technology, Lodz, Poland.

3. Instituto de Investigaciones Fisicoquímicas Teóricas y Aplicadas (INIFTA), Departamento de Química, Facultad de Ciencias Exactas, CONICET, Universidad Nacional de La Plata (UNLP), La Plata, Buenos Aires, Argentina.

4. Facultad de Cs. Veterinarias, UNLP, La Plata, Buenos Aires, Argentina.

Corresponding author: daiana.m.soto@gmail.com

Even when Pseudomonas aeruginosa pathogenicity has been well recognized by clinic medicine and vet literature, few it is known regarding to strains isolated from archaeological materials. Recent studies have demonstrated that strains of $P$. aeruginos $a$ with a high adaptive ability to colonize and develop biofilm in inorganic surfaces of archaeological ceramics exist [1].

The potsherds samples from which P. aeruginosa was isolated are of Rustic pottery (Fig. 1), usually for domestic, and they came from the archaeological site La Cuestecilla, Northern of La Rioja province, Argentina. To assess the bioadhesión and biofilm formation ability of this strain adapted to inorganic materials, experimental assays were performed with samples of the same ceramic type from which they were identify. Firstly, the strain was seeded on solid mineral medium [2] and then in contact with archaeological ceramics samples. The bioadhesion and biofilm formation was assessed after an incubation time by scanning electron miscroscopy (SEM-EDAX Fem Quanta $200^{\mathrm{TM}}$ - LIMF, UNLP). The samples were kept in a closed chamber with ethanol (100\%) for $24 \mathrm{~h}$. Previously to observation by scanning electron microscopy, a part of the samples were cleaned by utrasonic to evaluate biodeterioration processes in its surface, while the other were metalized with Au to increase image resolution to observe bioadhesion and biofilm formation. Potsherds without treatment were used as control samples and were analysed by stereomicroscopy (Olympus BH2, INIFTA-CONICET) and SEM. Cyanolichens colonized weakened ceramics surfaces by weathering and erosion processes (Fig. 1). The results proved that cyanolichens left biopits of subcircular shapes of approximated 0,5-1,5 mm (Fig. 2a) that later are used, along with surface irregularities, by P. aeruginosa to develop (Fig. 2b). Even though archaeological potsherds did not have clearly defined biofilms such as those obtained by experimentation, the production of exopolimeric substances (EPS) and biofilm formation by $P$. aeruginosa it is corroborate, such as its pathogenicity and risk in the handling of such cultural objects.

Keywords: archaeological potsherds, biofilm, microscopies, Pseudomonas aeruginosa 


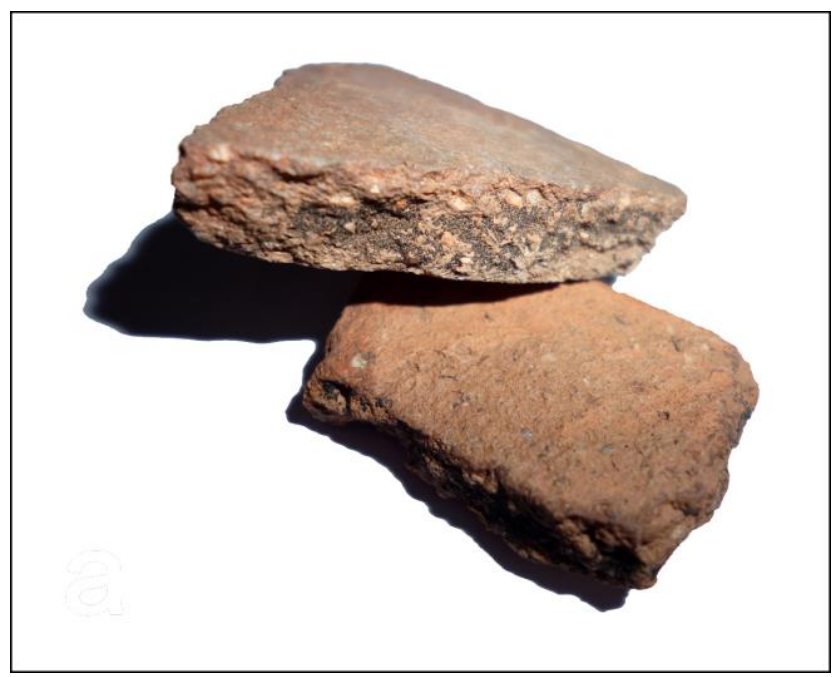

Figure 1. Control sample. Rustic potsherd colonized by cyanolichens in the edges and surface irregularities.

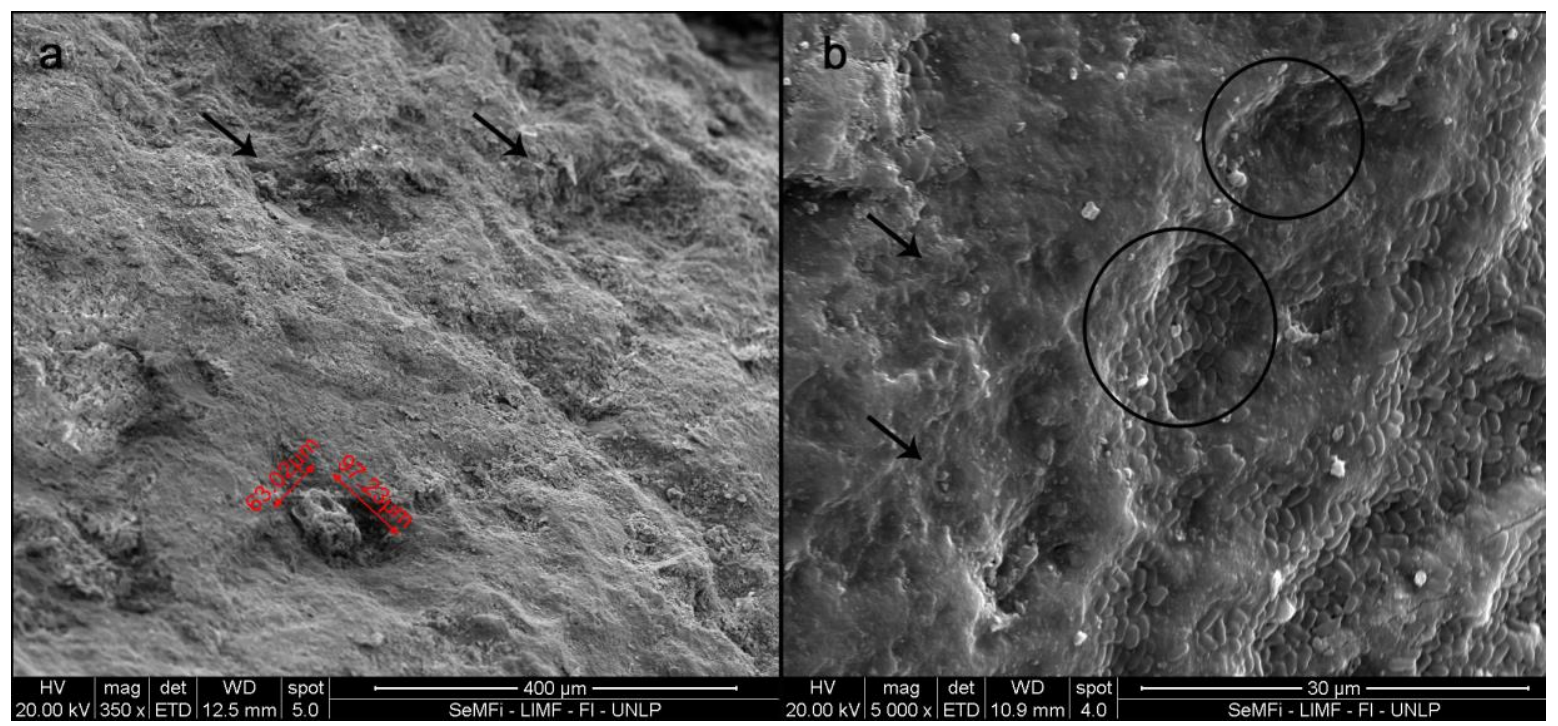

Figure 2. SEM-EDS. (a) Biopits left by cyanolichen thalli in potsherds surfaces (x350). (b) Experimental biofilm of $P$. aeruginosa development in cyanolichens attack zones. Circles point pits, arrows surface irregularities (x5000).

References:

[1] P. S. Guiamet, Soto D.M., Schultz M. Inter. Biodet. Biodeg. 141 (2019), p. 2-9.

https://doi.org/10.1016/i.ibiod.2018.10.003

[2] P. Lavín, Gómez de Saravia S. G., Guiamet P. S. Biofouling 30 (5) (2014), p. 561-569. http://dx.doi.org/10.1080/08927014.2014.897334

[3] This research was performed without funding but in collaboration with Lodz University of Technology (Poland) and INIFTA-CONICET (Argentina). 